\title{
पंडित ओमकारनाथ ठाकुर का भारतीय संगीत में योगदान आशुतोष शर्मा
} संगीत विभाग, आइ.सी.डी.ई.ओ.एल., हिमाचल प्रदेश विश्वविद्यालय, शिमला

अमूल्य रत्नों से परिपूर्ण जाज्वल्यमान भारत वसुंधरा का आँचल कितना सौभाग्यशाली, कितना पवित्र और कितना अनोखा है, यह किसी से छिपा नहीं है। यह रत्नमई भारत भूमि अपने अंतर मे जहाँ असंख्य मणि - मुक्ताएँ छिपाये बेठी है, वही इसके आँचल मे समय-समय पर ऐसे रत्न भी पैदा हुए, जिन्होंने अपनी तपस्या, सृजनात्मक क्षमता एवम परंपरागत कला की कठोर तपस्या के बल पर भारत की समृद्ध संस्कृति अक्षुण्ण बनाये रखने तथा उसके वैविध्यपूर्ण स्वरुप को नित नवीन विधि से संवारने सजाने एवम जन-जन के समक्ष उसे सही रूप में प्रस्तुत कर जनता को असीम आनंद-सौन्दर्य का बोध कराने मे अपना सर्वस्व अर्पित कर दिया। उन्हीं महान पुरुषों में हैं 'संगीतमार्तण्ड', 'पद्मश्री' ओमकारनाथ ठाकुर, जिनका नाम संगीताकाश में 'मार्तण्ड' की भांति आज भी देदीप्यमान है। संगीत जगत मे सम्मोहित आवाज से संगीत से अनभिज्ञ एवम रुचिहीन व्यक्ति को मंत्रमुग्ध करने वाले पंडित ओमकारनाथ ठाकुर अनोखे व्यक्तित्व एवम विशिष्ठ गायन शैली के कारण अपने जीवन काल मे ही बहुचर्चित रहे।

24 जून 1937 को गुजरात राज्य के जिला भादरान के जहाजग्राम में प्रणव-साधक पंडित गौरीशंकर के यहाँ जन्मे बालक ओमकारनाथ के जीवन का प्रारंभिक काल जहाँ संघर्षमय वातावरण मे व्यतीत हुआ, जिससे वह स्वावलंभी बने, वहीं योगी प्रणव साधक पिताश्री का प्रभाव पंडित जी के जीवन पर पड़ा, जिससे 'प्रणव' उनके समस्त जीवन का आधार एवम प्रेरणा बन गया। संयोग से पंडित जी के पिता गौरीशंकर एक विलक्षण महात्मा की संगत से ग्रहस्थ का लाभ छोड़कर ओमकार (प्रणव) की साधना में लीन हो गए। उन्ही दिनों पंडित गौरीशंकर को चौथे पुत्र रत्न की प्राप्ती हुई और उसका नामकरण 'ओमकार' कर दिया। पंडित ओमकारनाथ ठाकुर का आरंभिक जीवन पारिवारिक कलह आर्थिक संकट और पिता के वैराग्यमय जीवन के कारण बड़ा अभावग्रस्त और कष्टमय रहा। बेशक पिता जी के संस्कार के बल पर पंडित जी में अदभुत आत्मबल रहा फिर भी माताजी ने सभी प्रकार के संकटों का सामना कर, स्वयं श्रम कर अपनी चार संतानों पंडित जी उनके दो ज्येष्ठ भाई, पंडित बालकृष्ण एवम पंडित रविशंकर और एक बहन पार्वती का भरण-पोषण किया।

ओमकारनाथ की संगीत सिखने की ललक एवम गायन सुनकर भड़ोच के एक सज्जन सेठ शापूरजी को बालक ओमकार में कुछ असाधारण प्रतिभा दिखाई दी और वे उनको बम्बई लेकर गए। वहां उन्होंने बालक ओमकार को महान संगीताचार्ये "पंडित विष्णु दिगंबर पलुस्कर" जी के चरणों में सौंपकर शिष्यत्व ग्रहण कराने का श्रेय प्राप्त किया द्य केवल 13 वर्ष की आयु में ही पंडित विष्णु दिगंबर पलुस्कर जी के "गन्धर्व महाविधालय" मै संगीत शिक्षा हेतु दाखिल हो गए।

पंडित जी ने एक कलाकार के रूप में अपने गायन में गंभीर आलापचारी, कूट एवम कलिष्ट तानो का प्रयोग स्वर-संयोग, स्वर-भेद, उच्चारण-भेद, काकू-भेद आदि से एक ही शब्द के अनेक अर्थों का 
प्रयोग करना, इनके साथ आवाज़ भावुकता आदि विशिष्टताओं को (गायन में) प्रयुक्त कर गायन की एक स्वंतत्र शैली को संगीत श्रोताओं के सम्मुख प्रस्तुत किया। यह उनका सहस-कर्म ही कहकर पुकारा जाएगा, जब उन्होंने इटली के डिक्टेटर मुसोलिनी को पूरिया (कोमल धैवतयुक्त) गाकर सुला दिया था। यह उनकी विलक्षण प्रतिभा और उनके संगीत की निराली शक्ति का प्रदर्शन था।

पौधों-पत्तों पर संगीत का प्रभाव पड़ने का प्रयोग भी विज्ञान की प्रयोगशाला के किसी कौतुक से कम आश्चर्यजनक बात नहीं थी। इस घटना का उल्लेख करते हुए पंडित ओमकारनाथ ठाकुर ने एक और नई खोज संगीत-संसार के सामने रखी की संगीत द्वारा पौधों व पत्तों के प्रटोप्लार्म के कोष में संयत 'क्लोरोप्लास्म' विचलित ओर गतिमान हो उठता है। उन्होंने लोगों को बताया की वह अपनी प्रयोगशाला में स्वरों का सूक्षम अध्ययन करके इस तथ्य पर पहुचते हैं की फूलों, पत्तों और पौधों पर भी मधुर गायन के स्वरों का अलग-अलग प्रभाव पड़ता है। सर जे.सी. बोस ने वनस्पति-शास्त्र संबंधी विशेष अनुसन्धान द्वारा प्रमाणित कर दिया था की वनस्पति में भी जीव है। पंडित जी ने उनकी प्रयोगशाला मैं जाकर भैरवी गाई थी। गाने से पूर्व यंत्रों द्वारा पौधों व पत्तों की अवस्था देख ली गई थी और गायन के पश्चात उनपर आई हुई नई चमक का दर्शन भी लोगों ने किया था। संभवतः यह प्रयोग संगीत जगत में पहला था।

पंडित जी राग निर्माण के साथ साथ रागों के द्रष्टा भी थे। राग में प्रयुक्त स्वरों द्वारा निर्मित राग का स्वरुप तथा उस स्वरुप को भावपूर्ण शैली से प्रस्तुत करना ही गायक का परम लक्ष्य होना चाहिए। 'मैं नहीं माखन खायो' जैसे पद को गाते समय यदि गायक स्वयं को बालकृष्ण समझ ले तो उसका वांछित असर श्रोताओं पर पड़ सकता है। जोगी मत जा .. मत जा.. तथा राग नीलाम्बरी में 'ओ मितवा जाए बसों विदेस 'पंडित जी की प्रसिद्ध भावपूर्ण रचनाएँ हैं।

पंडित ओमकारनाथ ठाकुर एक सुयोग्य गुरु थे। वे क्रोधी भी थे, किन्तु शिष्यों को स्नेह से सिखाते थे। जहाँ एक शिक्षक के रूप में पंडित जी हैं भारतीय संगीत-जगत को अपनी कला के उत्तरदाई शिष्य के रूप हैं अनेक कुशल संगीतज्ञ प्रदान किये जिसमे प्रमुख हैं, डा० प्रेमलता शर्मा, (पूर्व उप-कुलपति खैरागढ़ संगीत विथ्वविद्यालय), डा० एन. राजन (पूर्व अध्यक्ष संगीत शास्त्र विभाग, काशी हिन्दू विश्वविद्यालय वाराणसी) प० बलवंत राय भट्ट, डा० प्रदीप कुमार दीक्षित, श्री अतुल देसाई आदि के नाम हैं। गायकों के अतिरिक्त पंडित जी की शिष्याओं में वायलिन वादिका डा० एन राजन ने बहुत प्रसिद्धि पाई है। उनके वायलिन वादन मैं पंडित जी की गायकी की झलक साफ़ दिखाई देती है।

भारतीय संगीत का प्रचार एवम प्रसार पंडित जी के जीवन का मुख्य लक्ष्य था, जिसे उन्होंने अपने असामान्य प्रतिभा के बल पर आन्तर्राष्ट्रीय ख्याति के शिखर तक पहुचाया। सन 1933 ई. में आपने यूरोप की यात्रा की और फ्लोरैंस नगर की अंतररास्ट्रीय संगीत परिषद् में भाग लिया। वर्ष 1952 में भारत सरकार द्वारा अफगानिस्तान भेजे गए, सांस्कृतिक प्रतिनिधित्व मंडल का नेतृत्व पंडित की ने ही किया। फिर वर्ष 1953 में बुडापेस्ट में 'शांति परिषद' के विश्व अधिवेशन में भारत का प्रतिनिधि बने और चेकोस्लोवाकिया हंगरी, नॉर्वे, स्वीडन आदि देशों में संगीत का प्रचार एवम प्रसार किया। वे भारतीय संगीत का शिखर इतना ऊँचा शिखर देखना चाहते थे की वह संसार के किसी भी कोने से 
दिखाई पद सके। उनके अकथनीय प्रयत्नों के फलस्वरूप ही भारतीय समाज में संगीत की गरिमा बढ़ी, उसका प्रचार प्रसार हुआ, कलाकारों का वर्ग राष्ट्र के प्रति उत्तरदाई बना, उन्हें समाज में उचित स्थान प्राप्त हुआ। साथ साथ पाश्चात्य जनता ना केवल भारतीय संगीत की और आकृष्ट हुई, अपितु उसके उसकी अन्तरात्मा को पहचानकर उसे अपनाने का भी प्रयत्न किया।

एक शिक्षाकार, प्रसाशक और संगठनकर्ता के रूप में पंडित जी ने महामना मदन मोहन मालवीय के सुपुत्र श्री गोविन्द मालवीय के सहयोग से सन 1950 में बनारस हिन्दू विश्वविद्यालय में 'श्री कला संगीत भारती' संगीत महा विद्यालय स्थापित करवाया जो भारत का सर्वप्रथम महाविद्यालय है, जहाँ संगीत के गीतं, वाद्यम तथा नृत्यम तीनों विधाओं में स्नातक, स्तर तक तथा स्नातकोत्तर शिक्षा देने की व्यवस्था है। कला की उच्चता और शिक्षण में प्रवीणता इन दोनों का एक में अवस्थान दुर्लभ है, किन्तु पंडित जी ने दोनों रूपों में अदभुत कुशलता का परिचय दिया।

पंडित जी द्वारा लिखित संगीत ग्रंथों का अध्ययन करने से यह सहज ही स्पष्ट हो जाता है की मध्य युग की सबसे बड़ी विडम्बना, संगीत के क्रिया एवम शास्त्र-पक्ष के बीच हुई चौड़ी खाई को दूर करने में वे पर्याप्त रूप से सफल हुए। उनके संगीत ग्रन्थ 'संगीतांजलि' (छह भागों में), 'प्रणव-भारती' और राग अने रस (गुजरती भाषा में) इस बात के साक्षी हैं कि क्रिया और शास्त्र पक्ष की खाई को पाटने का सत्प्रयास उन्होंने किया। एक विशिष्ठ वाग्गेयकार के रूप में ओमकारनाथ ही नहीं, 'प्रणवरंग' की विशिष्टता उन्होंने अभिप्रेत थी। 'सदारंग' और 'अदारंग' की भांति 'प्रणवरंग' उपनाम से उन्होंने अनेक छंदों में काव्य-रचना करके विभिन्न रागों में बंदिशों का निर्माण किया जो उनकी संगीतांजलि (छह भागों में) हमें प्राप्त है।

15 अगस्त 1947 को तत्कालीन गृह मंत्री सरदार वल्लभ भाई पटेल ने पंडित जी के द्वारा ही राष्ट्रगीत 'वन्देमातरम' (पूरा गीत) को आकाशवाणी के तत्कालीन सभी केंद्रों से प्रसारित करवाया था। वर्ष 1930 में नेपाल महाराज ने संगीत मार्तण्ड और वर्ष 1940 में विशुद्ध संस्कृत महाविद्यालय ने संगीत सम्राट की उपाधियों से पंडित जी को सम्मानित किया। वर्ष 1955 में गणतंत्र दिवस के शुभ अवसर पर भारत सरकार ने इनको "पद्मश्री" की उपाधि से सम्मानित किया। वर्ष 1963 में ओमकारनाथ ठाकुर को काशी विश्वविद्यालय द्वारा डी.लिट् की मानद उपाधि प्रदान की गई तथा वर्ष 1964 में रविन्द्र भारती विश्वविद्यालय द्वारा भी उन्हें यही उपाधि दी गई।

लगभग पचास वर्षों तक संगीत की विशेष सेवा करने वाले 'पदमश्री' पं. ओमकारनाथ ठाकुर का लगभग दो वर्षों की लंबी बीमारी के बाद 29 दिसंबर 1967 को रात्रि 1 बजे निधन हो गया। संगीत के साधक और उसके रसिकों के लिए यह अपूर्णीय क्षति थी। उनकी जो कृतियां शास्त्रों और रिकार्डों के रूप में विद्यमान हैं, वह आशा और प्रेरणा का कार्य करेंगी।

\section{संदर्भ}

1 (क) सुशिल चौबे : 'हिंदुस्तानी संगीत के रत्न' पृष्ठ $72-73$

(ख) सुशील मिश्रा : 'ग्रेट मास्टर्स ऑफ़ इंडियन म्यूजिक ', पृष्ठ 142

2 लक्ष्मी नारायण गर्ग ; 'संगीत- निबंधावली ', पृष्ठ 25 दृ 27 